\title{
Long-term behavior of the Kelvin waves revealed by CHAMP/GPS RO measurements and their effects on the tropopause structure
}

\author{
M. Venkat Ratnam ${ }^{1}$, T. Tsuda ${ }^{1}$, T. Kozu ${ }^{2}$, and S. Mori ${ }^{3}$ \\ ${ }^{1}$ Research Institute for Sustainable Humanosphere (RISH), Kyoto University, Uji, Japan \\ ${ }^{2}$ Faculty of Science and Engineering, Shimane University, Nishi-kawatsu Matsue, Japan \\ ${ }^{3}$ Institute of Observational Research for Global Change (IORGC), Yokohama-city, Japan
}

Received: 4 August 2005 - Revised: 20 December 2005 - Accepted: 22 December 2005 - Published: 3 July 2006

Part of Special Issue "The 11th International Symposium on Equatorial Aeronomy (ISEA-11), Taipei, May 2005"

\begin{abstract}
The vertical and temporal variations of Kelvin waves and the associated effects on the tropical tropopause were studied using long-term (from May 2001 to October 2005) CHAMP/GPS (CHAllenging Mini satellite Payload/Global Positioning System) radio occultation (RO) measurements. The periods of these waves were found to be varying in between 10 and 15 days, with vertical wavelengths $5-8 \mathrm{~km}$. These variations clearly show eastward phase propagation in the time-longitude section and eastward phase tilts with height in altitude-longitude, displaying the characteristics of Kelvin waves. The peak variance in the temperature is found over the Indian Ocean and into the western Pacific within the broad region of the equator. Kelvin wave amplitudes were found significantly enhanced in the eastward shear of the quasi-biennial oscillation (QBO) and are confined in and around the tropopause during westward phase of QBO, where it extends between 17 and $25 \mathrm{~km}$ during the eastward phase of QBO and is damped away above, consistent with earlier reported results. The amplitudes are increasing during the months of Northern Hemisphere winter and sometimes they are highly sporadic in nature. Seasonal and inter-annual variations in the Kelvin wave amplitudes near the tropical tropopause coincide exactly with the tropopause height and temperature, with a sharp tropopause during maximum Kelvin wave activity. A clear annual oscillation, along with a month-to-month coincidence is evident most of the time in both the tropopause height and Kelvin wave activity, with maximum and minimum Kelvin wave amplitudes during the Northern Hemisphere winter and summer, respectively. In addition, a signature of quasi-biennial oscillation (QBO) in the tropopause structure is also seen in long-term tropopause variations, although the amplitudes are less when compared to the annual oscillation. In the westward phase
\end{abstract}

Correspondence to: M. V. Ratnam

(vratnam@ rish.kyoto-u.ac.jp of QBO (during strong Kelvin wave activity) at $20 \mathrm{~km}$ (in 2001-2002 winter and 2003-2004 winter), the tropopause height was slightly larger with a sharp tropopause and low temperature. The process behind these observed features has been discussed.

Keywords. Meteorology and Atmospheric Dynamics (Middle Atmospheric Dynamics; Waves and tides; Convective processes)

\section{Introduction}

The interaction between tropical convection, atmospheric waves and the large-scale atmospheric circulation has been recognized as being crucial in the understanding of the dynamical processes in the equatorial atmosphere, such as perturbations ranging from meso-scale (gravity waves) to planetary spatial scales (tides, Kelvin waves, etc.) in the upper troposphere and lower stratosphere (UTLS) regions. Among the various atmospheric waves in the tropics, the Kelvin waves are the most dominant with a planetary scale and have great practical importance in the Earth's atmosphere. We employ in this study the CHAMP/GPS radio occultation (RO) data in 2001-2005, which provides a good opportunity to study the long-term behavior of Kelvin waves and their effects on the tropopause structure.

Using various observational techniques considerable progress has been attained in studying the Kelvin waves since their discovery by Wallace and Kousky (1968). These waves are eastward propagating (Matsuno, 1966), having periods from 3 to 20 days with vertical wavelengths of 5 to $12 \mathrm{~km}$ and are trapped within $15^{\circ}$ of the equator (Andrews et al., 1987; Tsuda et al., 1994; Shiotani et al., 1997; Holton et al., 2001; Mote et al., 2002). These waves are assumed to be generated particularly by convective forcing, and remarkable

Published by Copernicus GmbH on behalf of the European Geosciences Union. 
progress has been made in connecting the wave characteristics with the perturbations in cloud convection from outgoing long-wave radiation (OLR). Therefore, they are often called "convectively coupled" Kelvin waves which were also noticed with the pressure fields in the models (for example, Takayabu, 1994; Wheeler et al., 2000). Further, the upward propagating Kelvin waves have significant importance in stratospheric circulation, in addition to the gravity wave effects (Hitchman and Leovy, 1988).

A number of studies have been done using intensive radiosonde campaigns in characterising the Kelvin waves (Wallace and Kousky, 1968; Tsuda et al., 1994 and references therein; Sato et al., 1994; Holton et al., 2001; Shimizu and Tsuda, 1997; Fujiwara et al., 1998) and their impact on the tropopause. But network of these observations was small and hence the global morphology of Kelvin waves was poorly known. Later, satellite observations were used to study the global structures of the Kelvin waves. For example, Kelvin waves were studied using Nimbus- 7 by Salby et al. (1984) and using Microwave Limb Sounder (MLS) measurements with $\sim 2.7 \mathrm{~km}$ vertical resolution by Canziani et al. (1995), Srikanth and Ortland (1998), Mote et al. (2002) and using cryogenic limb array etalon spectrometer (CLAES), having a vertical resolution of $2.5 \mathrm{~km}$ by Shiotani et al. (1997). All the height resolutions of these observations are not good enough to retain the fine structures of Kelvin waves, which are sometimes confined to within the narrow layer near the tropopause.

A novel GPS RO technique has been introduced which is capable of providing global measurements with high accuracy and resolution. Tsuda et al. (2000) showed that the temperature fluctuations observed by GPS/MET occultations were appropriate for global studies of gravity wave activities in the stratosphere. Randel et al. (2003) also studied temperature variations in the tropical tropopause region with GPS/MET data and found characteristics of Kelvin waves, although the observation periods by GPS/MET were restricted to limited times.

The German (CHAMP) and Argentine (SAC-C) satellites were successfully launched in 2000. Using one-year data from CHAMP and SAC-C, for the first time, Tsai et al. (2004) showed the evidence of the Kelvin waves in the UTLS region. Randel and Wu (2005) extended the study with special emphasis on how these Kelvin waves are influenced by background stratospheric winds and showed the link to tropical deep convection.

The present study further extends the analysis of Tsai et al. (2004) and Randel and Wu (2005), however, considering larger data set giving more statically significant results. Much attention has been given to find the extent of various background parameters on the observed Kelvin wave amplitudes by utilizing long-term CHAMP/GPS RO measurements, particularly emphasizing modulation of the tropopause structure by these Kelvin waves in more detail.

\section{Database}

\subsection{Long-term global data: CHAMP/GPS RO observations}

The CHAMP/GPS satellite was launched on 15 July 2000 into an almost circular and near polar orbit (with the inclination of $87^{\circ}$ ) with an initial altitude of $454 \mathrm{~km}$; see Reigber et al. (2000) for the system details. The first occultation measurement was performed on 11 February 2001, and since then, about 150-200 occultations per day have been recorded. For the present study, we use the level 3 version 005 data from May 2001 to October 2005, which were produced by the GeoForschungsZentrum (GFZ), Potsdam, using their standard method for the RO processing; see Wickert et al. $(2001 ; 2005)$ for more details of the data analysis, its processing, initial results and validation. In comparison with radiosonde data, the temperature bias in the CHAMP/GPS $\mathrm{RO}$ data is less than $0.5 \mathrm{~K}$. The height resolution varies from 0.4 to $1.5 \mathrm{~km}$ near the tropopause. The latitudinal and longitude distribution of the radio occultations can be seen in Schmidt et al. (2004). Data has been interpolated to $200 \mathrm{~m}$ and considered in the height range between 10 and $30 \mathrm{~km}$.

\subsection{Long-term Singapore radiosonde data}

For background wind information over the equator, longterm radiosonde observations over Singapore $\left(1.36^{\circ} \mathrm{N}\right.$, $103.98^{\circ} \mathrm{E}$, Station number: 48698$)$, with height coverage up to $30 \mathrm{~km}$ from January 2001 to November 2005, has been utilized. The entire data has been interpolated to a height interval of $200 \mathrm{~m}$, in accordance to CHAMP/GPS RO observations.

\subsection{Satellite outgoing long-wave radiation observations}

The daily gridded outgoing long-wave radiation (OLR) data provided by the NOAA Climate Diagnostics Center website (http://www.cdc.noaa.gov), interpolated in $2.5^{\circ} \times 2.5^{\circ}$ latitude-longitude grids, have been archived during January 2001 to August 2005 and used as a proxy for tropical deep convection.

\section{Background conditions}

The long-term monthly mean zonal velocity from January 2001 to November 2005 observed at Singapore is plotted in the contour plot of Fig. 1a. The zonal wind velocity, having oscillation of 24-26 months (Quasi-biennial oscillation) with downward phase propagation, can be clearly noticed, particularly from $17 \mathrm{~km}$ and above, with peak amplitudes around $28-\mathrm{km}$ altitude. There exists two complete cycles of QBO during the entire GPS RO used for the present study, with westward and eastward directions during November 2001-March 2002, December 2003-April 2004 and April 2002-November 2003, May 2004-October 2005, 

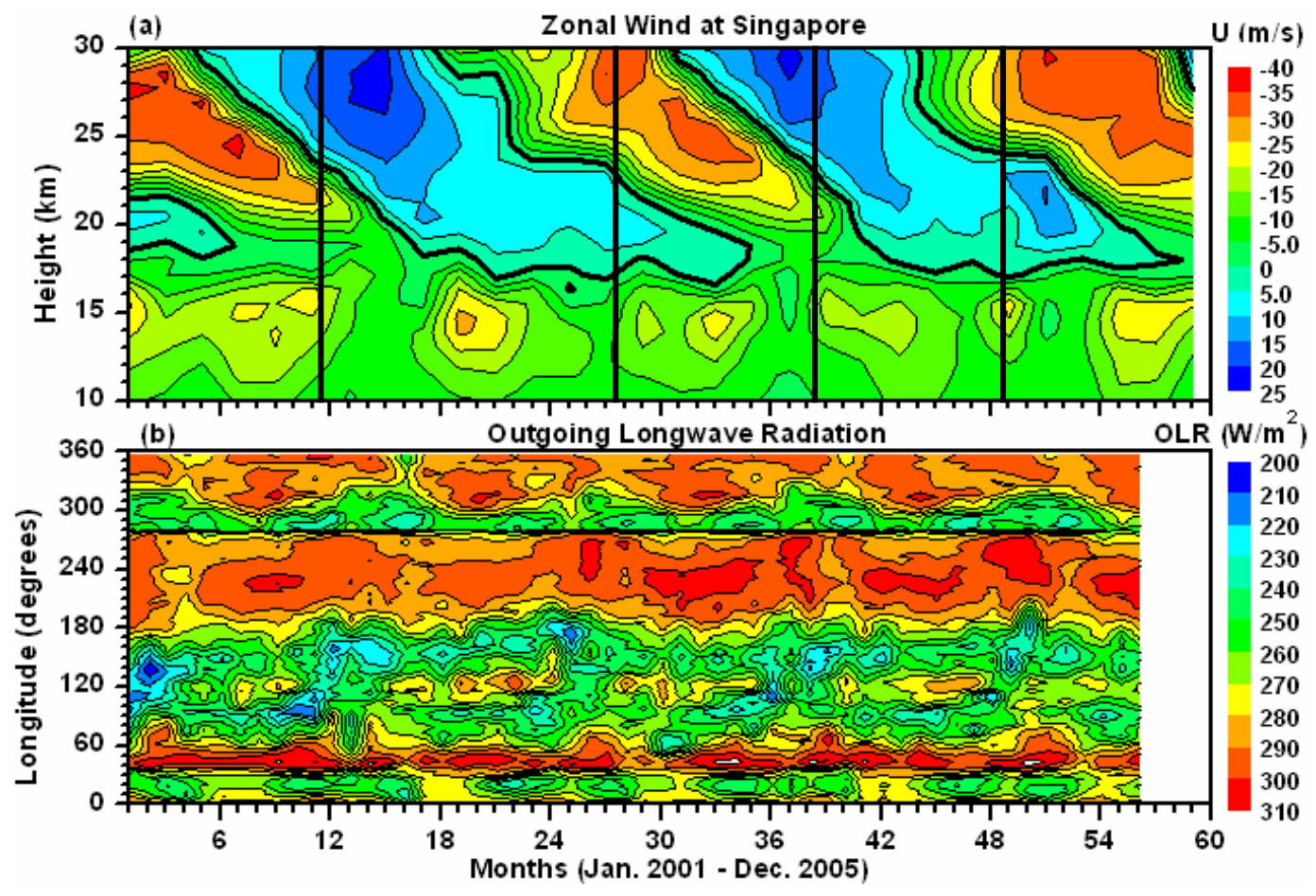

Fig. 1. Height-time cross section of (a) monthly mean zonal wind (m/s) observed during January 2001 to November 2005 at Singapore. The vertical lines show the times of different phases of QBO considered for further analysis. (b) Longitude-time section of outgoing long-wave radiation (W/m²) observed during January 2001 to August 2005. Blue regions (low OLR values) correspond to an area of deep convection.

respectively, around the 20-km altitude. The westward winds are always noticed below $17 \mathrm{~km}$ with peak amplitudes around $14.5 \mathrm{~km}$ during the Asian monsoon months (June-August), although the intensity is smaller than at mid-latitudes.

The longitude-time section of OLR observed from January 2001 to August 2005 is shown in Fig. 1b. Note that enhanced convection (low OLR values) is particularly occurring in between the $60^{\circ} \mathrm{E}$ and $180^{\circ} \mathrm{E}$ longitudes (Indian ocean to Pacific), with significant enhancements during the Northern Hemisphere winter months. There exists another enhancement over the South American continent (around $300^{\circ} \mathrm{E}$ longitude), however, restricted to a narrow region with less intensities when compared to the former case.

\section{Long-period oscillations (Kelvin waves)}

The global variability of the Kelvin waves has been studied using long-term CHAMP/GPS RO observations. Previous studies reveal that the dominant wave number is 1 and/or 2 (Mote et al., 2002; Tsai et al., 2004; Randel and Wu, 2005). For the extraction of Kelvin waves with dominant wave numbers 1 and 2, using GPS measurements, the procedure implemented by Tsai et al. (2004) is closely followed. In brief, we have selected latitudes within \pm 10 deg from the equator, considering that Kelvin waves are dominant in $\pm 15 \mathrm{deg}$ (Mote et al., 2002). Tsai's procedure involves three steps.
First, 30-day median profiles (15 days before and after) were removed to obtain temperature fluctuations (Ts). In order to avoid the contribution by inertia-gravity waves, in the second step profiles are further smoothed in altitude, with a cutoff at $4 \mathrm{~km}$ using 2 Chebyshev low-pass filter, considering that the inertia-gravity waves often have vertical wavelengths of about 2-3 km (Tsuda et al., 1994; Shimizu and Tsuda, 1997; Ratnam et al., 2006. Finally, to isolate dominant wave numbers along longitude, a fitting function,

$f(x)=\sum_{s=1}^{2} A_{s} \sin s\left(x-\phi_{s}\right)$.

is used. The mixing of the wave numbers 1 and 2 components is then applied to best fit the $T s$ at $10-30 \mathrm{~km}$ (hereafter called fitted $T s$ ). The amplitude $A s$ and phase $\phi s$ for all longitudes $x$ are solved by means of a nonlinear least-squares method.

Figure 2 shows the longitude-time distribution of RO which occurred in between $10^{\circ} \mathrm{N}$ and S from May 2001 to October 2005. In total, 14936 occulations almost equally distributed in all the longitudes are considered. Although the number of occultations significantly increased after February 2002, a greater number of occulations can be noticed from July 2003 in the equatorial latitudes. Since CHAMP/GPS is a polar orbiting satellite with an inclination angle of $87^{\circ}$, there are, on average, only 10-13 occultations per day near the equator. Instead, $T s$ and fitted $T s$ are 


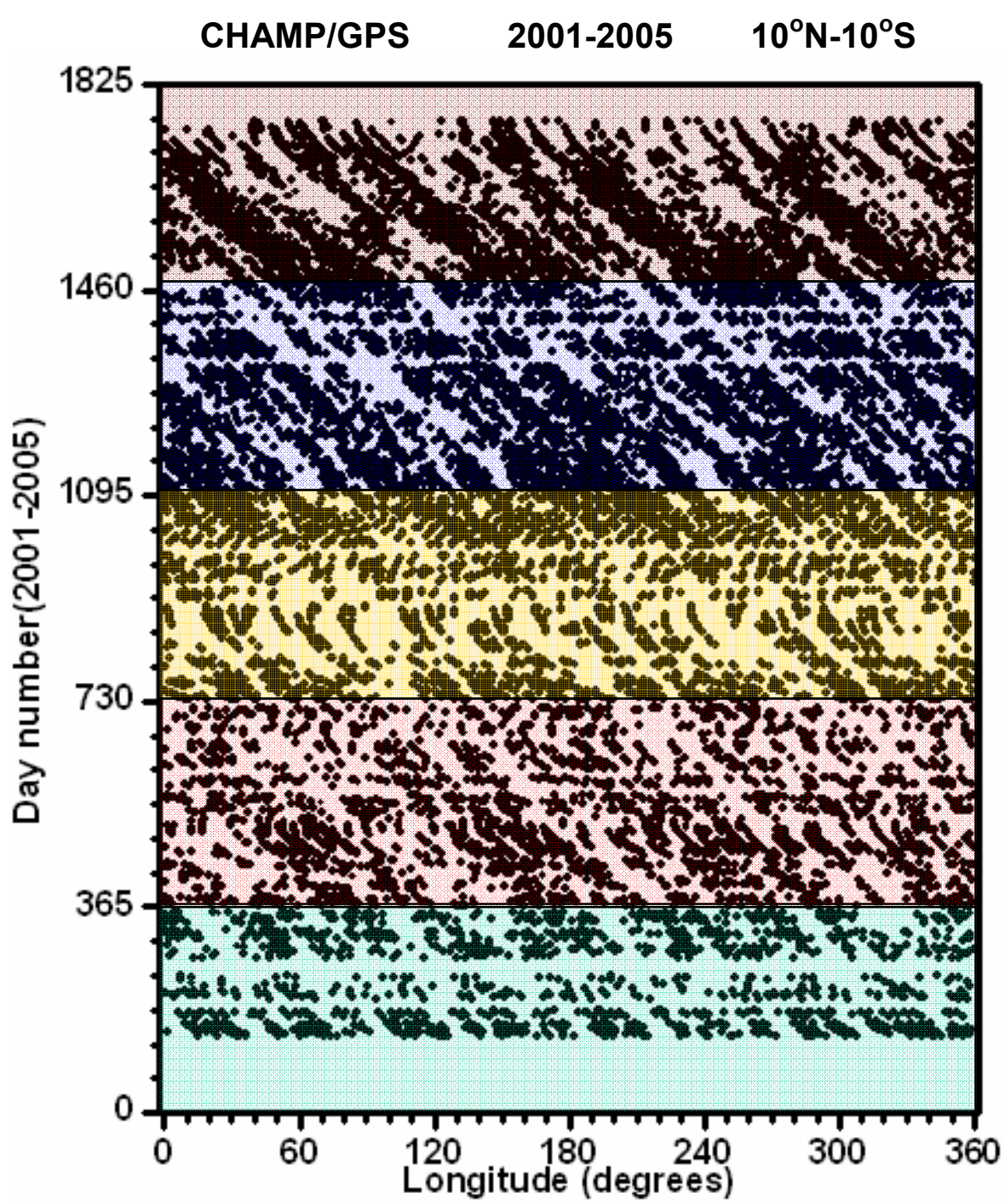

Fig. 2. Longitude-time distribution of CHAMP GPS Radio Occultations (RO) observed in between $10^{\circ} \mathrm{N}$ and S during May 2001 to October 2005.

constructed by using 3 adjacent day's data, vertically shifted to the middle date (3-day running fitting). This method can be effectively used to study the Kelvin waves with periods greater than 10 days and with reduced amplitudes for less than 7-day oscillations (Tsai et al., 2004; Randel and Wu, 2005).

Kelvin wave amplitudes determined with CHAMP/GPS RO measurements are compared by using intensive radiosonde (CPEA) campaigns conducted over the Indonesian maritime continent (Tsuda et al., 2006), which reported a considerable decrease for the former, mainly due to the sinusoidal fitting along the longitude and a smoothing by spherical symmetric assumptions. Nevertheless, GPS RO data gives important information on the global variability of the Kelvin waves. Temperature fluctuations also showed a clear eastward phase propagation in the time-longitude section
(Tsai et al., 2004). Here we discuss the generation of Kelvin waves and their interaction wind with the background zonal wind, along with the effects on the tropopause on a long-term basis.

\subsection{Long-term variations of Kelvin waves by CHAMP/ GPS RO measurements}

Since previous studies with GPS RO data reveal the major features of Kelvin waves (Tsai et al., 2004; Randel and Wu, 2005; Tsuda et al., 2006), we study the long-term characteristics of the Kelvin waves, especially under different background wind conditions. Note that Randel and $\mathrm{Wu}$ (2005) already presented the Kelvin wave characteristics during one complete cycle of QBO. Figure 3 shows the timelongitude sections of the fitted $T s$ contours at $20-\mathrm{km}$ altitude, 


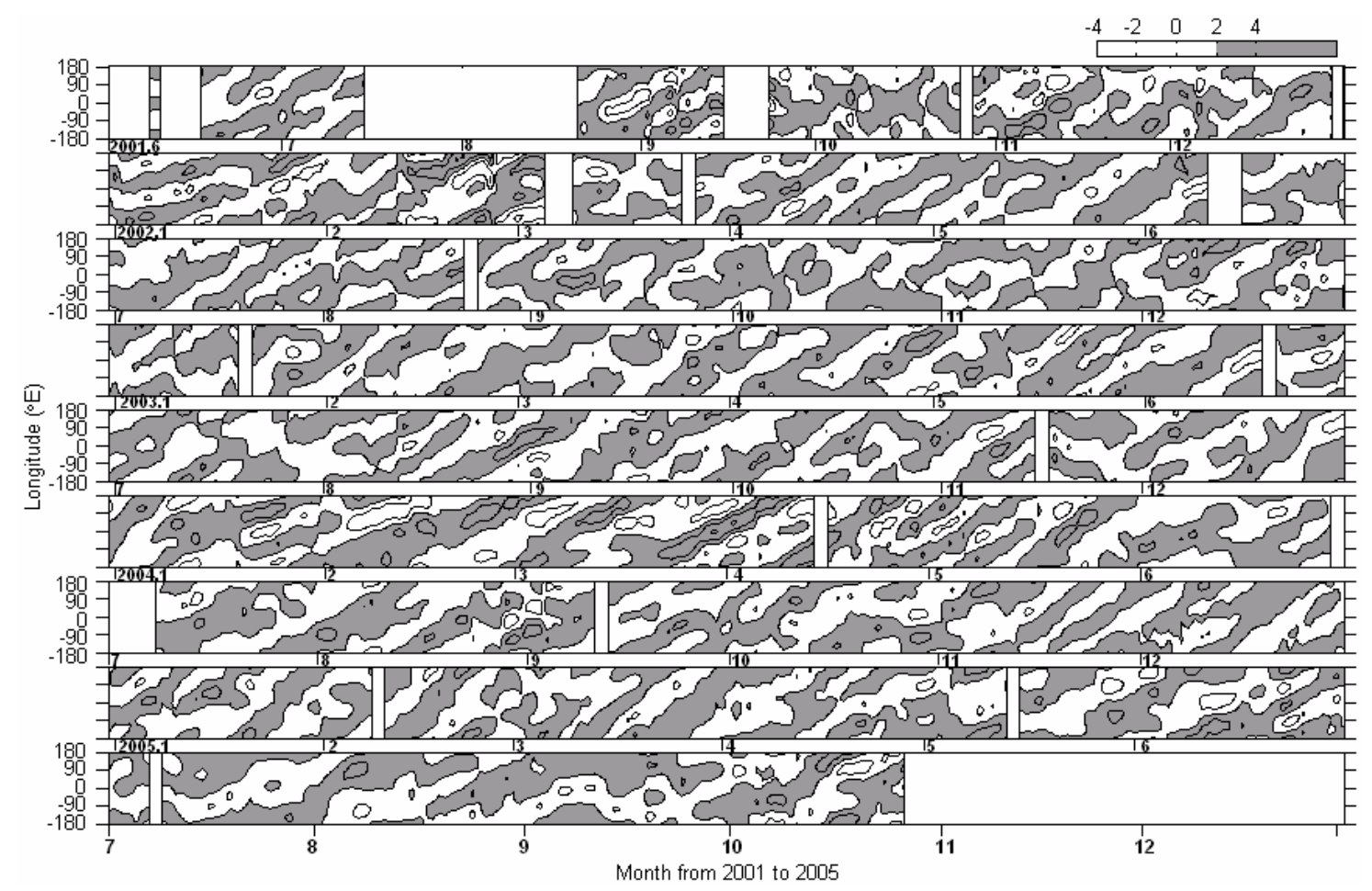

Fig. 3. Time-longitude sections of fitted $T s$ contours at $20-\mathrm{km}$ altitude, constructed from wave 1 and wave 2 components between June 2001 and October 2005. The month number starts from the first of each month and the vertical blank periods indicate the missing data. The positive and negative perturbations are shown in gray and white colors, respectively. Note that this is the extension figure of Tsai et al. (2004).

constructed by a 3-day running fitting for wave numbers 1 and 2 between 1 June 2001 and 31 October 2005. (This is an extension figure of Fig. 4 in Tsai et al., 2004 with three additional years of data.) The time series of the waves were generally regular and nearly periodic with eastward phase progression. The wave amplitude is about $2 \mathrm{~K}$, in general, and can reach up to $4 \mathrm{~K}$ around January-February 2002 and also during March-April 2004. An eastward phase progression is clearly seen most of the time, but the phase progression is sometimes random and obscured, for example, in October 2001, mid June 2002 and the early months of 2003. Most $T s$ patterns show mixed waves dominating the entire period; however, few pairs of positive/negative $T s$ patterns along the longitude indicate a dominant wave number 2, for example, during the mid August-mid September 2001, JanuaryFebruary 2002, mid April-mid May, July 2002, mid Januarymid February 2004 and end of April-mid May 2004, November 2004, and March 2005.

\subsection{Amplitude and phases of Kelvin waves at $20 \mathrm{~km}$}

In order to define the dominant wave number of Kelvin waves, long-term variations of amplitudes and relative phases of both wave numbers 1 and 2 at $20 \mathrm{~km}$ are shown in Fig. 4. The phase progression indicates that the dominant wave period is from 10 to 20 days, mostly in between 10 and
15 days. As seen in Fig. 4b, most of the time, wave number 1 is dominant, but wave number 2 component coexists. Both the wave numbers 1 and 2 show similar time variations, possibly either due to having the same generation source or a predominance of background wind effects which acts similarly on both wave numbers.

Enhanced wave amplitudes were seen clearly from November 2001 to February 2002 and also in January-May 2004. Most of these features had already been reported by Tsai et al. (2004) and also by Randel and Wu (2005). Another striking feature noticed is that wave number 2 is dominant, particularly during eastward shear, and throughout the year, 2003 wave number 1 is dominant.

\subsection{Generation of Kelvin waves}

We further report on the long-term characteristics of Kelvin waves under different background conditions, including convective activity and background wind conditions, which can be related to the generation of Kelvin waves and wave mean flow interaction, respectively.

Figure 5a shows the long-term Kelvin wave amplitudes of both wave numbers 1 and 2 at $17-\mathrm{km}$ altitude in 20012005, and Fig. 5b shows the OLR deviations from a yearly mean for both zonal average and also the average in between $60^{\circ} \mathrm{E}$ and $180^{\circ} \mathrm{E}$ longitude in the $10^{\circ} \mathrm{N}$ to $10^{\circ} \mathrm{S}$ latitudes. 


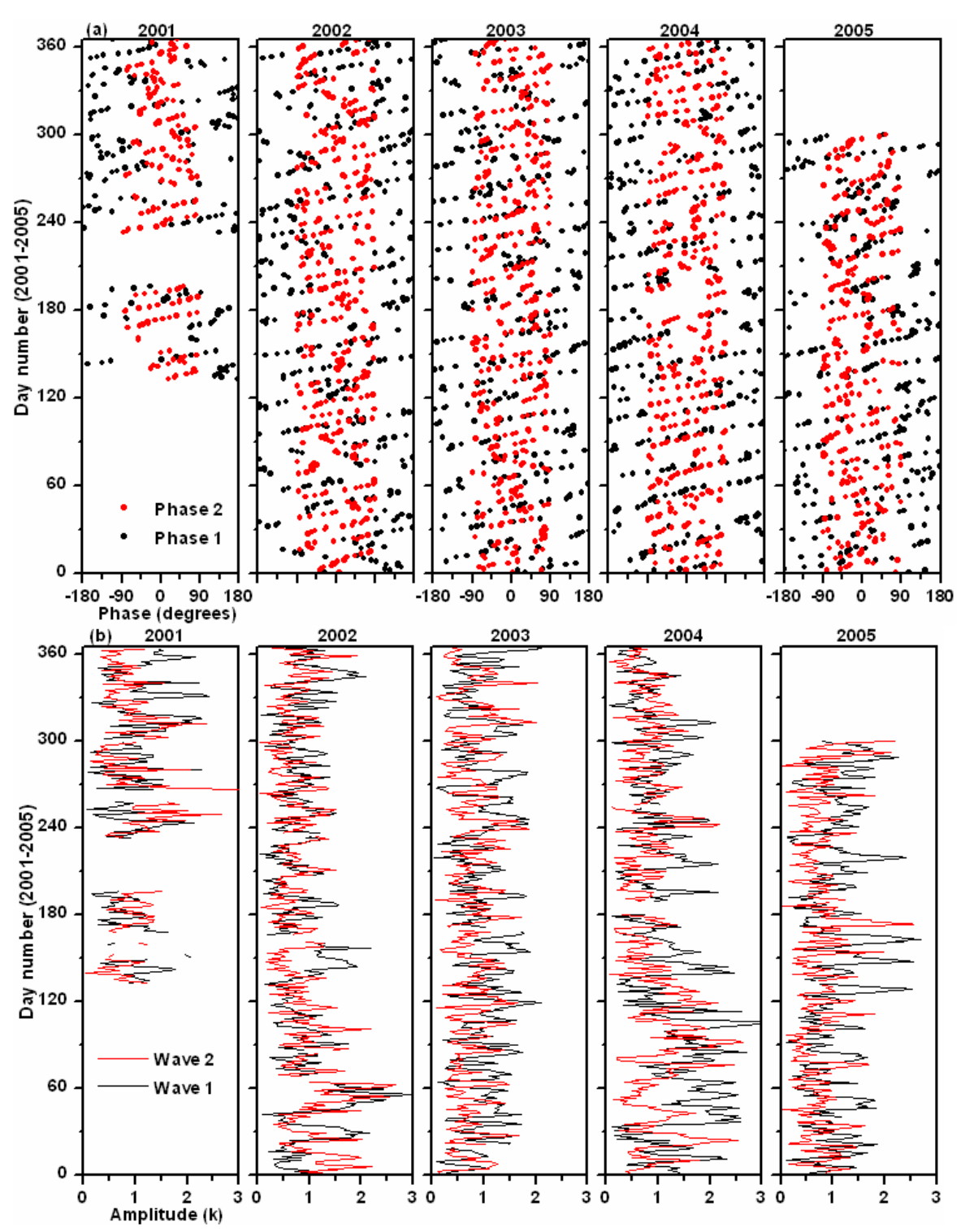

Fig. 4. Long-term time series of (a) phases and (b) amplitudes of both wave numbers 1 (black) and 2 (red) observed using CHAMP/GPS observations at the $20-\mathrm{km}$ altitude region.

Note that the OLR variations averaged over the longitude band mentioned above clearly follow the zonal mean averaged OLR variations plotted in the same figure, revealing that most of the convection is observed from Indian Ocean to Pacific. This figure also reveals that the peak amplitudes of Kelvin waves are mostly linked to tropical deep convection (negative OLR values), either with wave numbers 1 and/or 2 which are known as convectively coupled Kelvin waves, although they are not always matching exactly.

The correlation coefficients plotted in Figs. $5 \mathrm{c}$ and $\mathrm{d}$ in between zonal averaged OLR and the amplitudes of Kelvin waves with wave numbers 1 and 2 shows only 0.29 but have a significant correlation $(R=-0.52)$ with the OLR in between the $60^{\circ} \mathrm{E}$ and $180^{\circ} \mathrm{E}$ longitude. These results are consistent with that reported by Randel et al. (2003) and also by Randel and Wu (2005), using GPS/MET and also by the limited data of CHAMP/GPS RO. However, this kind of correlation is only observed on a long-term basis and will decline in the individual cases, although a lag of a few days can be noticed sometimes. Wheeler et al. (2000) observed a slight lag between the OLR and the associated perturbations in the upper troposphere. In addition, an improved correlation has been noticed by Randel and Wu (2005) in lagging the temperature perturbations with respect to OLR. They also reported that this correlation will decay when we move to higher heights, where the influence of the background zonal wind will become significant. A striking feature to be noticed is the annual oscillation in both OLR anomalies and also the Kelvin 

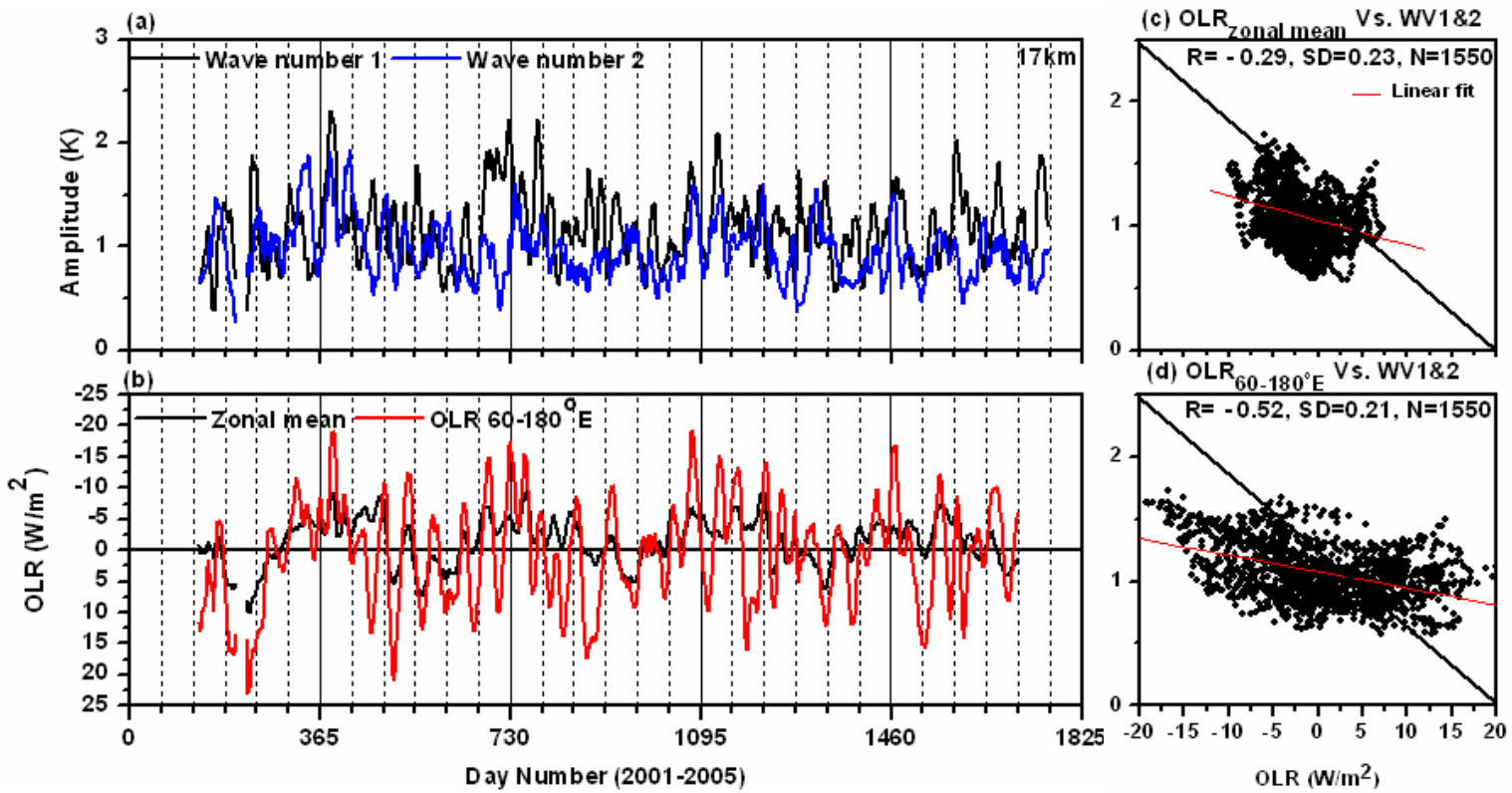

Fig. 5. Long-term time series of (a) Kelvin wave amplitudes of wave numbers 1 and 2 observed using CHAMP/GPS measurements at the $17-\mathrm{km}$ altitude region. (b) Corresponding outgoing long-wave radiation (OLR) anomalies (from yearly mean) observed in between $10^{\circ} \mathrm{N}$ and $10^{\circ} \mathrm{S}$ averaged in between $60^{\circ} \mathrm{E}$ and $180^{\circ} \mathrm{E}$ longitude (red) and $180^{\circ} \mathrm{W}$ to $180^{\circ} \mathrm{E}$ (zonal average) longitude (black). For clarity a 15 -day running mean was applied in both panels. Cross correlation observed between the amplitudes of Kelvin waves with both the wave numbers (c) vs. zonal mean OLR anomalies and (d) vs. $60^{\circ} \mathrm{E}$ and $180^{\circ} \mathrm{E}$ longitude band.
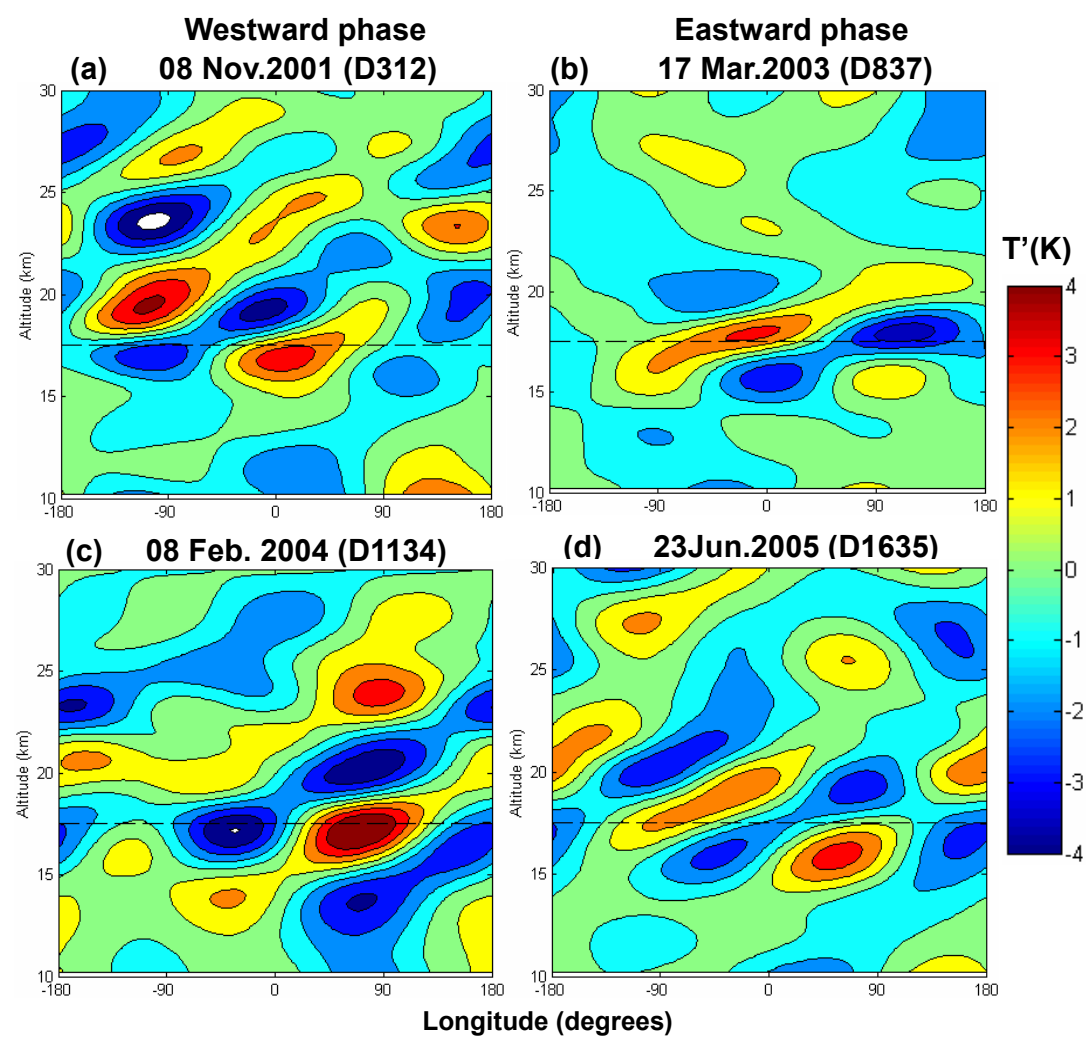

Fig. 6. Examples showing the altitude-longitude sections of fitted $T s$ observed in westward (left panels) and eastward (right panels) phases of QBO during the periods shown with vertical lines in Fig. 1a. Note that \pm 1 -day observations are considered to the day/ day number (from 1 January 2001) mentioned on the top of each panel. 


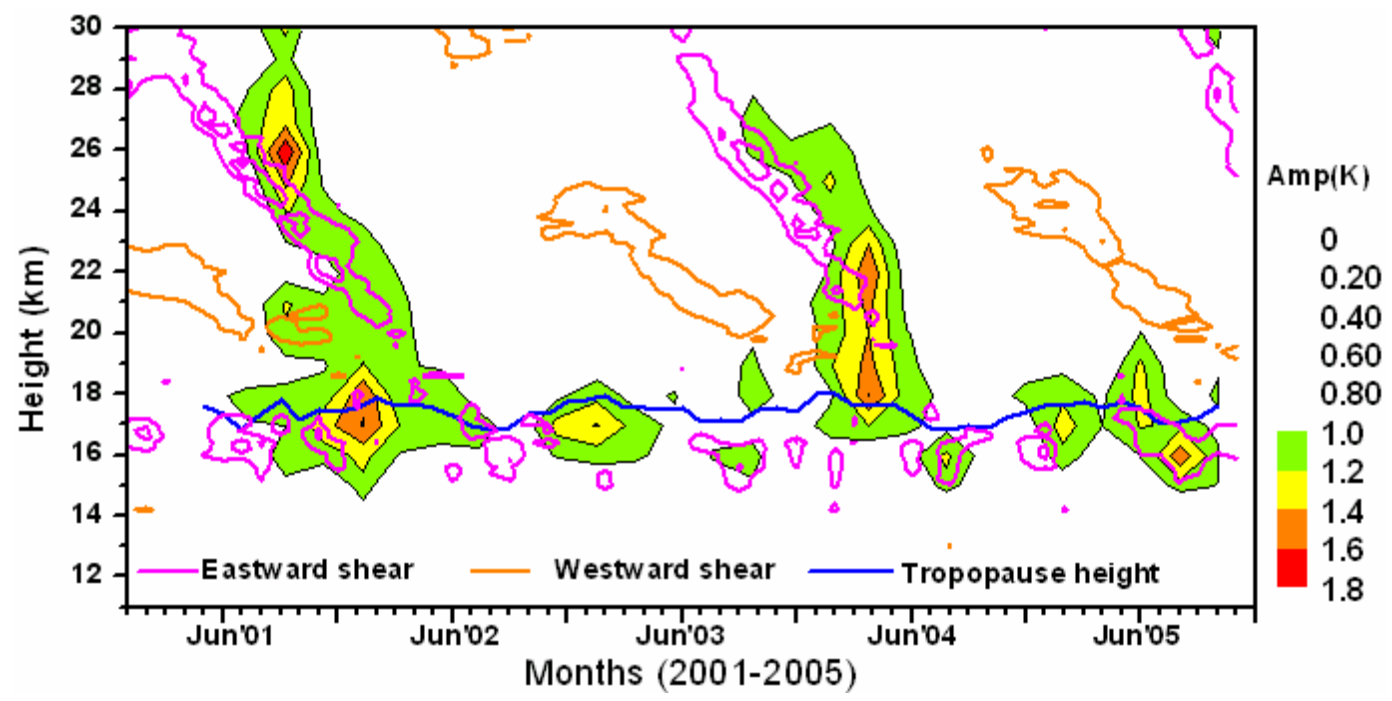

Fig. 7. Time-height variations of Kelvin wave amplitudes (colored contours) observed at equatorial latitudes $\left( \pm 10^{\circ}\right)$ using CHAMP/GPS during May 2001-October 2005, using both wave numbers 1 and 2 (averaged). Vertical shear in the eastward (magenta) and westward (orange) wind observed at Singapore is plotted in line contours. The contours are $\pm 0.1,0.2,0.3, \ldots \mathrm{m} / \mathrm{s} / \mathrm{s}$ and the contours with zero magnitude are omitted. Monthly mean tropopause height (blue line) observed in between $0-120^{\circ} \mathrm{E}$ longitude band is also plotted. Note that this is the extension figure of Randel and Wu (2005).

wave amplitudes, which will be discussed in more detail in Sect. 5.

\subsection{Interaction of Kelvin waves with background wind}

Figure 6 shows examples of the altitude-longitude section of fitted $T s$ for 4 cases (each with adjacent 3 days) during different phases of QBO. The amplitudes are significantly enhanced near the tropopause in all the cases but during the westward phase of QBO (Figs. 6a and c), the enhancement is noticed from $15 \mathrm{~km}$ onwards, extending up to $25 \mathrm{~km}$, but confined around the tropopause during the eastward phase of QBO (Figs. 6b and d). In all the cases the phase progression tilts eastward and upward and is nearly regular. The vertical wavelengths are estimated to be $\sim 7 \mathrm{~km}$ and $\sim 5 \mathrm{~km}$ during the westward and eastward phases of QBO, respectively, which are also consistent with that reported by Tsai et al. (2004) and Randel and $\mathrm{Wu}$ (2005). Since the large perturbations are located in and around the tropopause, the tropopause structure will be significantly modified by the Kelvin waves which will be discussed in detail in Sect. 5 .

A similar analysis was performed throughout the height region (17-30 km) for the entire time series (2001-2005) and is shown in Fig. 7. This figure shows time-height variations of the amplitudes of the wave numbers 1 and 2 (averaged) from May 2001 to October 2005, along with the background monthly mean zonal wind shear (line contours) taken from Singapore radiosonde data. Enhancement of the wave amplitudes can be clearly seen in relation to the downward phase propagation of the background westward phase of QBO (or near strong eastward shear zone) at all the heights, particu- larly from $18 \mathrm{~km}$ and above. This strong relation with the background winds is most likely due to thermal damping as proposed by Shiotani and Horinouchi (1993), using a longterm (15 years) rawinsonde data set from Singapore which is been reconfirmed using CHAMP/GPS RO data by Randel and $\mathrm{Wu}$ (2005). Kelvin waves don't exist above the $20-\mathrm{km}$ altitude during all the periods, expect during a strong eastward shear. The amplitudes of the Kelvin waves are significantly enhanced near the tropopause, which is also plotted in Fig. 7. Predominant annual variation in both Kelvin wave amplitudes and the tropopause can be noticed, with a peak occurring during the Northern Hemisphere winter. The amplitudes of the Kelvin waves also show the signature of QBO.

A few differences can be noticed from the earlier studies with these long-term characteristics. Although a clear enhancement in the amplitudes is noticed in relation to the downward phase propagation of the background westward wind, a maximum enhancement in the amplitudes of Kelvin waves is, however, observed near the strong eastward shear (near $26 \mathrm{~km}$ ) only in the first cycle of QBO. However,this maximum enhancement in the Kelvin wave amplitudes is observed significantly below the zones of the maximum eastward shear in the second cycle.

In order to estimate the impact of different background conditions at different altitude regions on the observed Kelvin wave amplitudes, a cross correlation analysis has been performed between the amplitudes, zonal wind and OLR, and is depicted in Fig. 8. A reasonable correlation $(\mathrm{R}=-0.52)$ between Kelvin wave amplitudes and OLR (negative correlation) is observed as expected around the tropical 
tropopause (around $17 \mathrm{~km}$ ). The first maximum correlation seems to occur below $12 \mathrm{~km}$. It can be noticed that the background wind plays a significant role on the observed Kelvin wave amplitudes only above the $23-\mathrm{km}$ altitude (positive correlation), with a peak around $27-28 \mathrm{~km}$, the region of maximum shear. There is a strong negative correlation especially near the tropopause between the Kelvin wave amplitudes and the zonal wind, giving evidence that the amplitudes are independent of background wind conditions near the tropopause.

\section{Effect on the tropopause}

Earlier studies reported that the Kelvin waves significantly affect the thermal structure around the tropopause (Tsuda et al., 1994), such as the dehydration and cirrus formation ( $\mathrm{Fu}-$ jiwara et al., 1998). Production of enhanced turbulence associated with Kelvin wave breaking near the tropopause could play an important role in the Stratospheric-Tropospheric (ST) exchange, causing a downward mixing of the stratospheric ozone into the troposphere (Fujiwara et al., 2003). Although a few studies were done earlier in relating the effects on the tropopause by the Kelvin waves, further research on longterm basis is still needed.

The effect on the tropopause height by these Kelvin waves is studied in much detail, using long-term CHAMP/GPS RO measurements, by separating the tropical region into three major longitudinal bands, each having similar tropopause variations (Ratnam et al., 2005). Figure 9 shows the temporal variation of the anomalies (deviation from the four and half years mean) of cold point tropopause height, temperature, and the tropopause sharpness observed from May 2001 to October 2005 near the equator $\left( \pm 5^{\circ}\right.$ latitudes) at 0 $120^{\circ} \mathrm{E}, 120-240^{\circ} \mathrm{E}$, and $240-360^{\circ} \mathrm{E}$ longitudinal bands. The tropopause sharpness $\left(\mathrm{S}_{T P}\right)$ is defined as the change in vertical temperature gradient across the tropopause:

$S_{T P}=\frac{T_{T P+\Delta z}-T_{T P}}{\Delta Z}-\frac{T_{T P}-T_{T P-\Delta z}}{\Delta Z}$

with $\Delta \mathrm{Z}=1 \mathrm{~km}$, where $T_{T P}$ is CPT temperature and $T_{T P \pm \Delta z}$ is the temperature at $1 \mathrm{~km}$ above (for + ) and below (for - ) CPT (Wirth, 2000). Since a sharp tropopause in tropics occurs mainly when there is an adjustment between the radiation (in stratosphere) and the convection (in troposphere), focus on this parameter will give important information on when and where the radiative-convective equilibrium occurs (Highwood and Hoskins, 1998).

It can be noted that these three longitudinal bands show slightly different features, although in general clear annual variations can be noticed in all three parameters at all longitudinal bands. The tropopause height and sharpness (temperature) becomes maximum (minimum) during the Northern Hemisphere winter (summer) months. However, maximum and minimum tropopause height variations shown in Fig. 9b vary from one longitudinal band to the other, for example,

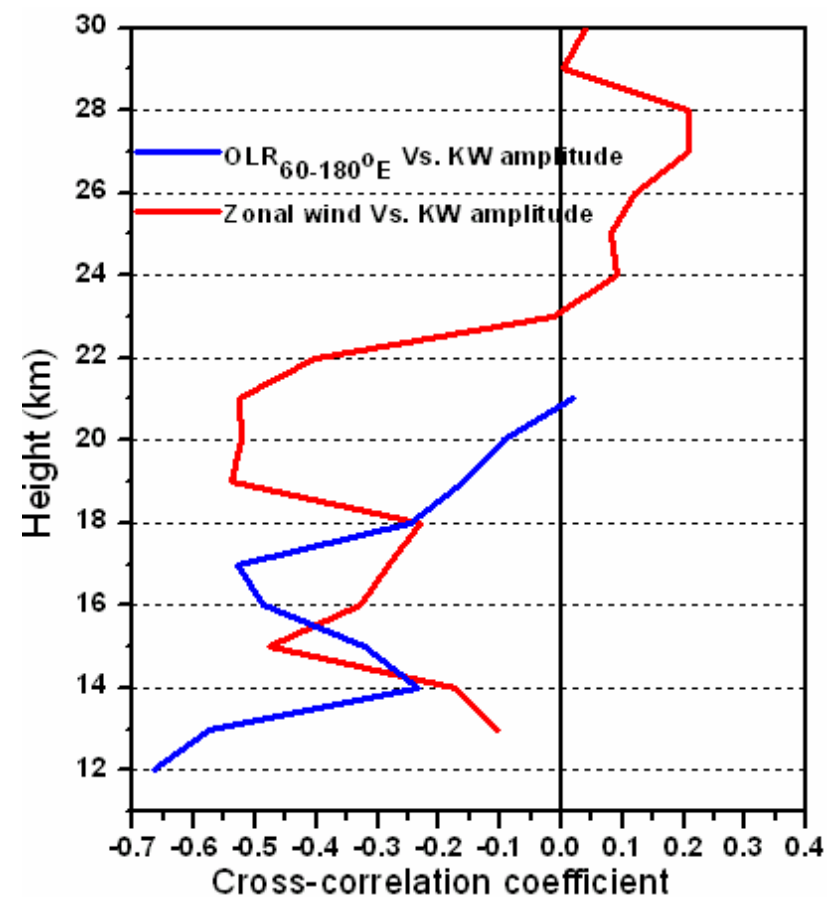

Fig. 8. Cross correlation observed in between the amplitudes of the Kelvin waves and the background wind (red line) and OLR data from $60-180^{\circ} \mathrm{E}$ longitude band (blue line) observed during May 2001 to October 2005.

at $120-240^{\circ} \mathrm{E}$ the tropopause height is slightly lower and higher during the Northern Hemisphere summer of the year 2002 and 2004, respectively, when compared to other longitudinal bands. The anomalies of the Kelvin wave amplitudes at $17 \mathrm{~km}$ for the wave numbers 1 and 2 in Fig. 9a also show the annual variation similar to the tropopause height (plotted for $0-120^{\circ} \mathrm{E}$ longitude). Note that the month-to-month coincidence of Kelvin wave activity and tropopause height is matching well most of the time, along with dominant annual variation. The correlation coefficient of the month-to-month comparison between these two parameters gives 0.56.

In addition, a signature of QBO is also evident, although small when compared to annual variations (clearly seen in the smoothed variations shown in Fig. 9b) from the interannual variations which can be inferred from the background zonal wind plotted in Fig. 9c. In the westward phase of QBO (during the strong Kelvin wave activity) at $20 \mathrm{~km}$ (in 20012002 winter and 2003-2004 winter), the tropopause height is slightly higher, the temperature is lower, and the sharpness is larger. Even though the four and half year analysis presented here cannot represent the actual trend as that presented using the long-term data set (Highwood and Hoskins 1998; Hoinka 1998; Randel et al., 2000; Seidel et al., 2001), most of the features,like the indirect response to the tropospheric convection, and the effect of QBO, etc., are consistent with earlier studies. 


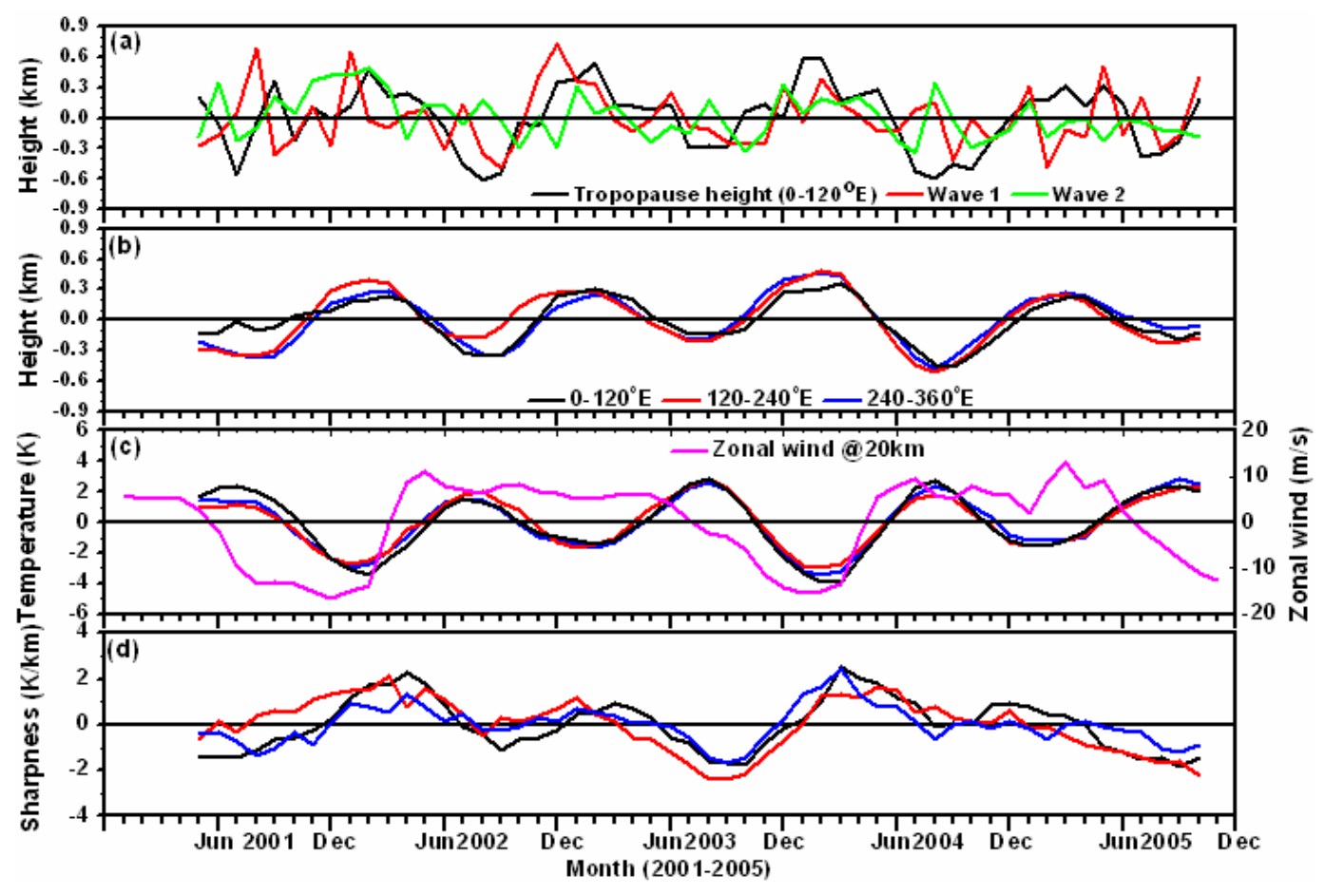

Fig. 9. Temporal variation of anomalies derived from climatological means (four and half years) of (a) the cold point tropopause height (black) observed at the equator $\left( \pm 5^{\circ}\right)$ at $0-120^{\circ}$ E longitude during May 2001-October 2005. Amplitudes of Kelvin waves for both wave numbers 1 (red) and 2 (green), observed at $17-\mathrm{km}$ altitude is also plotted. (b) Tropopause height observed at the equator $\left( \pm 5^{\circ}\right)$ at $0-120^{\circ} \mathrm{E}$, $120-240^{\circ} \mathrm{E}$, and $240^{\circ} \mathrm{E}-360^{\circ}$ longitude bands. Note that a 5-month smoothing was applied for this panel to show the interannual variations. Corresponding temporal variation of anomalies observed in (c) temperature, and (d) tropopause sharpness (see text). Monthly mean zonal velocity (magenta) observed at $20 \mathrm{~km}$, taken from Singapore radiosonde, is plotted in (c) and the amplitudes are shown on the right side. Mean tropopause height, temperature and sharpness are found to be $17 \mathrm{~km}, 191 \mathrm{~K}$, and $10 \mathrm{~K} / \mathrm{km}$, respectively.

The inference is that the tropopause structure is affected by the convection which has an annual cycle, thereby showing an annual oscillation. It also has a monthly variation which arises mainly due to the modulation by the Kelvin wave activity with a sharp tropopause at the equator. Since both are from the same source, if vertical propagation exists in the individual cases of Kelvin waves, all the phases should cancel out each other when averaging long-term, leaving no residual variations. However, the annual oscillation is still seen in the Kelvin wave amplitudes, near the tropopause, perhaps due to the additional source from the quasi-stationary waves that are frequently observed over the Indian Ocean to the maritime continent, as suggested by Randel and Wu (2005).

The influence of QBO on the tropopause structure can be inferred through the wind shear where a descending eastward shear is responsible for warm perturbations which will warm up and lower the tropopause (Figs. $9 \mathrm{~b}$ and c during the Northern Hemisphere winter of 2002). Alternatively, descending westward shear will raise and cool the tropopause, as shown in Figs. $9 \mathrm{~b}$ and $\mathrm{c}$ during the Northern Hemisphere winter of 2001 and the early months of 2004.

\section{Summary and discussion}

A detailed study on the vertical and temporal characteristics of equatorial Kelvin waves and their effects on the tropical tropopause has been presented using long-term CHAMP/GPS RO measurements under different background conditions in relation to convective activity (source region) and also under different background wind conditions. Temperature fluctuations clearly showed eastward phase propagation in the time-longitude section (Fig. 3). By using OLR data the major centers of convective activity associated with MJO were found to be most prominent over the warm pool regions of the eastern hemisphere, starting from the central Indian and western Pacific Oceans (between $60^{\circ} \mathrm{E}$ and $180^{\circ}$ ) (Rui and Wang, 1990), picking up especially over the Maritime continent and to the east (Fig. 1b). The eastward moment of these convective centers is clear during the Northern Hemisphere winter when the warm pool extends from the Indian Ocean to the date line, consistent with that reported by Lau and Shen, (1988). These convective centers will create perturbations which will move in all directions, depending upon the background wind especially to the east (Kelvin waves), sometimes clearly correlating with 
the convective centers (Fig. 5d) known as "convective coupled" Kelvin waves, and this effect is seen up to the tropical tropopause (around $17 \mathrm{~km}$, from Fig. 8).

Since Kelvin wave amplitudes are seen at maximum near the tropopause, hence they sometimes modify the tropopause structure significantly with the coldest tropopause. The Kelvin waves, which are known as "Free mode" Kelvin waves, move up vertically, even above the tropopause and their vertical propagation depends on background wind conditions mainly above the 23-km altitude (Fig. 8). The dissipation of Kelvin waves will depend on the vertical component of group velocity which decreases with the increase of the height. Therefore, eastward propagating Kelvin waves will generally dissipate in the eastward shear zones (Fig. 7). Hence, when the background wind is eastward, the Kelvin waves are observed in and around tropopause with less vertical wavelengths (Figs. 6b and d), whereas they extend to higher heights during the westward phase of QBO with large vertical wavelengths (Figs. 6a and c). The amplitudes of Kelvin waves are significantly enhanced only during strong eastward shear in the zonal wind (Fig. 7), which is consistent with the earlier reported literature (Shiotani and Horinouchi, 1993; Randel and $\mathrm{Wu}, 2005)$. However, this enhancement is not always seen especially during the second cycle presented here but noticed significantly at lower heights, which is inconsistent with earlier studies. Since the relation of OLR with the amplitudes of Kelvin waves is seen at $17 \mathrm{~km}$, whereas with the background wind starts from $23 \mathrm{~km}$ onwards, it is difficult to say which parameter will play a role for the observed enhanced amplitudes in between 17 and $23 \mathrm{~km}$, which demands further research.

The modification of the tropopause structure is also noticed during strong Kelvin wave activity. A month-to-month coincidence is seen most of the time between Kelvin wave amplitudes and the tropical tropopause. From long-term measurements of CHAMP/GPS, a clear annual variation in tropopause height, temperature and sharpness is seen in relation to the Kelvin wave amplitudes. Vertically propagating Kelvin waves in individual cases should cancel out each other in the long-term averaging, leaving no residuals but still the annual oscillation is clearly seen. This could be perhaps due to an additional source by quasi-stationary waves, which are frequently observed over the Indian Ocean to the maritime continent (Randel and $\mathrm{Wu}, 2005)$. In addition, a signature of stratospheric QBO is also seen in the tropopause height, although the amplitude of variation is small when compared to the annual oscillation, possibly due to wind shear arising from the different phases of QBO. During the westward phase of QBO, cold anomalies will raise the tropopause height by lowering the temperature with a sharp tropopause. The tropopause height will be decreased with higher temperatures and relatively less sharpness by warm anomalies during the eastward phase of QBO.
Acknowledgements. We thank H.-F. Tsai, T. Horinouchi, T. Nakamura, Y. Shibagaki for their fruitful discussions and comments on the manuscript. We also wish to thank GFZ (GeoForschungsZentrum), Potsdam for providing CHAMP/GPS RO data through the ISDC (INTEGRAL Science Data Centre ISDC) data center. One of the authors (MVR) wishes to thank JSPS (Japan Society for Promotion of Sciences) for providing fellowship to carry out this work. This work is also supported partially by MEXT (Japanese Ministry of Education, Culture, Sports, Science and Technology) using Grant-in-Aid for Scientific Research on Priority Areas (Grant number: (A03) 13136206; (A04) 13136203).

Topical Editor U.-P. Hoppe thanks two referees for their help in evaluating this paper.

\section{References}

Andrews, D. G., Holton, J. R., and Leovy, C. B.: Middle Atmospheric Dynamics, Academic Press, San Diego, California, 1987.

Canziani, P. O., Holton, J. R., Fishbein, E. F., and Froidevaux, L.: Equatorial Kelvin wave variability during 1992 and 1993, J. Geophys. Res., 100, 5193-5202, 1995.

Fujiwara, M., Kita, K., and Ogawa, T.: Stratosphere-troposphere exchange of ozone associated with the equatorial Kelvin waves as observed with ozonesondes and rawinsondes, J. Geophys. Res., 103, 19173-19 182, 1998.

Fujiwara M., Xie, S.-P., Shiotani, M., Hashizume, H., Hasebe, F., Vömel, H., Oltmans, S. J., and Watanabe, T.: Upper tropospheric inversion and easterly jet in the tropics, J. Geophys. Res., 108, 4796, doi:10.1029/2003JD003928, 2003.

Highwood, E. J., and Hoskins, B. J.: The tropical tropopause, Quart. J. Roy. Meteorol. Soc., 124, 1579-1604, 1998.

Hitchman, M. H. and Leovy, C. B.: Estimation of the Kelvin wave contribution to the semiannual oscillation, J. Atmos. Sci., 45, 1462-1475, 1988.

Hoinka, K. P.: Statistics of the global tropopause pressure, Mon. Weather Rev., 126, 3303-3325, 1998.

Holton, J. R., Joan Alexander, M., and Boehm, M. T.: Evidence for short vertical wavelength Kelvin waves in the Department of Energy-Atmospheric Radiation Measurement Nauru99 radiosonde data, J. Geophys. Res., 106(D17), 20 125-20 130, 2001.

Lau, K. M. and Shen, S.: On the dynamics of intra-seasonal oscillations and ENSO, J. Atmos. Sci.,45, 1781-1797, 1988.

Matsuno, T.: Quasi-geostrophic motion in the equatorial area, J. Meteo. Soc. Japan, 44, 25-42, 1966.

Mote, P. W., Dunkerton, T. J., and Wu, D.: Kelvin waves in stratospheric temperature observed by the Microwave Limb Sounder, J. Geophys. Res., 107(D14), ACL 10-1, 2002.

Randel, W. J., Wu, F., and Gaffen, D. J.: Inter-annual variability of the tropical tropopause derived from radiosonde data and NCEP reanalysis, J. Geophys. Res., 105, 15 509-15 523, 2000.

Randel, W. J., Wu, F., and Rivera Ríos, W.: Thermal variability of the tropical tropopause region derived from GPS/MET observations, J. Geophys. Res., 108(D1), 4024, doi:10.1029/2002JD002595, 2003.

Randel, W. J. and Wu, F.: Kelvin wave variability near the equatorial tropopause observed in GPS radio occulation measurements, J. Geophys. Res., 110, doi:10.1029/2004JD005006, 2005. 
Ratnam, M. V., Tsuda, T., Kozu, T., and Mori, S.: Gravity wave characteristics over equator observed during CPEA campaign using simultaneous multiple stations data, J. Meteorol. Soc. Japan, in press, 2006.

Ratnam, M. V., Tsuda, T., Shiotani, M., and Fujiwara, M.: New Characteristics of the Tropical Tropopause Revealed by CHAMP/GPS Measurements, Scientific Online Letters on Atmosphere , 1, 185-188, doi: 10.2151/sola. 2005-048, 2005.

Reigber, C., Lühr, H., and Schwintzer, P.: CHAMP mission status and perspectives, Suppl. to EOS, Transactions, AGU, 81, 48, F307, 2000.

Rui, H. and Wang, B.: Development characteristics and dynamic structure of tropical intra-seasonal convection anomalies, J. Atmos. Sci., 47, 357-379, 1990.

Salby, M. L., Hartmann, D. L., Bailey, P. L., and Gille, J. C.: Evidence for equatorial Kelvin modes in Nimbus-7 LIMS, J. Atmos. Sci., 41, 220-235, 1984.

Sato, K., Hasegawa, F., and Hirota, T.: Short-period disturbances in the equatorial lower stratosphere, J. Meteorol. Soc. Japan., 72, 859-872, 1994.

Schmidt, T., Wickert, J., Beyerle, G., and Reigber, C.: Tropical tropopause parameters derived from GPS radio occultation measurements with CHAMP, J. Geophys. Res., 109(D1), 3105, doi:10.1029/2004JD004566, 2004.

Seidel, J. D., Ross, R. J., Angell, J. K., and Reid, G. C.: Climatological characteristics of the tropical tropopause as revealed by radiosondes, J. Geophy. Res., 106, 7857-7878, 2001.

Shimizu, A. and Tsuda, T.: Characteristics of Kelvin waves and gravity waves observed with radiosondes over Indonesia, J. Geophys. Res., 102, 26, 159-26,171, doi:10.1029/96JD03146, 1997.

Shiotani, M. and Horinouchi, T.: Kelvin wave activity and the quasi-biennial oscillation in the equatorial lower stratosphere, J. Meteorol. Soc. Japan., 71, 175-182, 1993.

Shiotani, M., Gille, J. C., and Roche, A. E.: Kelvin waves in the equatorial lower stratosphere as revealed by cryogenic limb array etalon spectrometer temperature data, J. Geophys. Res., 102, $26131-26140,1997$.

Srikanth, R. and Ortland, D. A.: Analysis of Kelvin waves in HighResolution Doppler Imager and Microwave Limb Sounder stratosphere measurements using a constrained least square method, J. Geophys. Res., 103, 23 131-23 151, 1998.
Takayabu, Y. N.: Large-scale cloud disturbances associated with equatorial waves. Part I: Spectral features of the cloud disturbances, J. Meteorol. Soc. Jpn., 72, 433-449, 1994.

Tsai, H.-F., Tsuda, T., Hajj, G., Wickert, J., and Aoyama, Y.: Equatorial Kelvin waves observed with GPS occultation measurements (CHAMP and SAC-C), J. Meteorol. Soc. Japan., 82, 397406, 2004.

Tsuda, T., Murayama, Y., Wiryosumarto, H., Harijono, S. W. B., and Kato, S.: Radiosonde observations of equatorial atmospheric dynamics over Indonesia, 1, Equatorial waves and diurnal tides, J. Geophys. Res., 99, 10 491-10 505, 1994.

Tsuda, T., Nishida, M., Rocken, C., and Ware, R. H.: A global morphology of gravity wave activity in the stratosphere revealed by the GPS occultation data (GPS/MET), J. Geophys. Res., 105(D6), 7257-7273, 2000.

Tsuda, T., Venkat Ratnam, M., Kozu, T., and Mori, S.: Behavior of the Kelvin waves during intensive radiosonde campaigns and comparison with CHAMP/GPS measurements, J. Meteorol. Soc. Japan, in press, 2006.

Wallace, J. M. and Kousky, V. E.: Observational evidence of Kelvin waves in the tropical stratosphere, J. Atmos. Sci., 25, 900-907, 1968.

Wheeler, M., Kiladis, G. N., Webster, P. J.: Large-scale dynamical fields associated with convectively couples equatorial waves, J. Atmos. Sci., 57, 613-639, 2000.

Wickert, J., Reigber, C., Beyerle, G., Konig, R., Marquardt, C., Schmidt, T., Grunwaldt, L., Galas, R., Meehan, T. K., Melbourne, W. G., and Hocke, K.: Atmosphere sounding by GPS radio occultation: First results from CHAMP, Geophys. Res. Lett., 28(17), 3263-3266, 2001.

Wickert, J., Beyerle, G., Koenig, R., Heise, S., Grunwaldt, L., Michalak, G., Reigber, C., and Schmidt, T.: GPS radio occultation with CHAMP and GRACE: A first look at a new and promising satellite configuration for global atmospheric sounding, Ann. Geophys., 23, 653-658, 2005.

Wirth, V.: Thermal versus dynamical tropopause in upper tropospheric balanced flow anomalies, Quart. J. Roy. Meteor. Soc., 126, 299-317, 2000. 